\title{
Stacked T-Shaped Strips Compact Antenna for WLAN and WiMAX Applications
}

\author{
M. Karthikeyan ${ }^{1} \cdot$ R. Sitharthan ${ }^{2} \cdot{\text { Tanweer } \mathrm{Ali}^{3} \text { (D) } \cdot \text { Sameena Pathan }}^{4}$. \\ Jaume Anguera ${ }^{5}$. D. Shanmuga Sundar ${ }^{6}$
}

Accepted: 9 October 2021 / Published online: 29 October 2021

(c) The Author(s) 2021

\begin{abstract}
A compact triple band antenna with stacked T-shaped strips inside a rectangular ring monopole has been proposed. This novel structure with a slot in the defected ground achieves triple band opration i.e. 2.47-2.77 GHz, 3.3-3.7 GHz and 5.10-6.62 GHz. These bands find application in important wireless communication standards like WiMAX (3.3-3.8 GHz, and 5.25-5.85 GHz, WLAN (2.4 G-2.5 GHz, 5.1-5.3 GHz, and 5.72-5.85 GHz). The antenna is printed on a FR-4 substrate with an overall dimension of $33 \times 17 \times 1.6 \mathrm{~mm}^{3}$. An impedance bandwidth of $11 \%(2.47-2.77 \mathrm{GHz}), 11 \%(3.3-3.7 \mathrm{GHz})$ and $25 \%(5.10$ $6.62 \mathrm{GHz}$ ) is obtained. A good conjunction between the simulated and measured results is inferred from the antenna design analysis.
\end{abstract}

Keywords Ring monopole $\cdot$ Slots $\cdot$ T shaped strips $\cdot$ WLAN $\cdot$ WiMAX

\section{Introduction}

Compact printed monopole antennas with multiband operation is gaining attention as a result of the tremendous development of compact devices for wireless applications [1, 2$]$. Antenna is the main component of wireless communication devices for adopting standards like WLAN, WiMAX etc. Now a days market demand for compact wireless portable

Tanweer Ali

tanweer.ali@manipal.edu

1 School of Electronics Engineering, Vellore Institute of Technology, Vellore, India

2 School of Electrical Engineering, Vellore Institute of Technology, Vellore, India

3 Department of Electronics and Communication Engineering, Manipal Institute of Technology, Manipal Academy of Higher Education, Manipal, India

4 Department of Information and Communication Technology, Manipal Institute of Technology, Manipal Academy of Higher Education, Manipal, India

5 Fractus Antennas, Barcelona, Spain and Electronics and Telecommunication Department, Universtat Ramon Llull, Barcelona, Spain

6 Laboratorio de Superficies y Nanomaterials, Facultad de Ciencias Fiscas y Matematicas, Universidad de Chile, Santiago, Chile 
device is increasing rapidly. Hence, in regard to this demand, design of miniaturized multiband antenna has attracted many researchers [3-6]. Multiband antenna works for more than one standard is vital component for portable devices. Modified monopole antennas is considered as proficient among other antennas structures due to its simplest structures [7, 8].

The literature details various dual and multiband antennas [9-20]. In [9], a pair of L-shaped strips are combined to obtain triple band operation. However, large antenna dimension (i.e., $33 \times 28 \mathrm{~mm}^{2}$ ) is a major drawback. Two self similar ring radiator was designed in [10] for achieving triple band operation with a dimension of $38 \times 25 \mathrm{~mm}^{2}$. This antenna size is also large for compact devices. Li et al. [11] proposed a rectangular ring monopole antenna exhibiting triple band operation is designed using L-strips and inverted T-shaped stubs. In [12], L-Shaped strips on a $30 \times 42 \mathrm{~mm}^{2}$ substrate are used to obtain tri-band operation. Similarly, CPW fed slotted antenna with relatively larger dimension has been proposed in $[13,14]$. Li et al. [15] proposed a triple band antenna that satisfies WLAN and WiMAX standards by employing fork shaped strips within a rectangular ring. The multiband operation is exhibited in [16] using fractal antenna using Koch iteration, however antenna size is considerably bigger i.e., $33.5 \times 23.5 \mathrm{~mm}^{2}$. Recently, in [17], using split ring resonator (SRR) a single narrowband at $1.1 \mathrm{GHz}$ and ultra wide band (UWB) operation ranging from 2.3 to $6.1 \mathrm{GHz}$ have been reported with an large antenna size of about $34 \times 44 \mathrm{~mm}^{2}$. A $\lambda / 4$ rectangular stub loaded with metamaterial for $2.45,3.5$ and $5.8 \mathrm{GHz}$ frequency bands has been designed in [18]. In [19], a fractal multiband antenna with Sierpinsiki triangle geometry with L-Shaped strips was reported. With a defected ground structure and compact slot, UWB antenna was presented in [20]. However, it exhibits less gain at operating frequencies. However, smaller antenna operational bandwidth and large size continues to remain the major loopholes in the aforementioned antenna designs.

In this research article, a compact tri-band antenna of $33 \times 17 \mathrm{~mm}^{2}$ dimensions with four T-shaped strips stacked one above another inside a rectangular ring monopole is proposed. The antenna operating bands are $2.47-2.77 \mathrm{GHz}, 3.3-3.7 \mathrm{GHz}$ and $5.10-6.62 \mathrm{GHz}$. The effect of adding strips on frequency and impedance matching are detailed. The parametric analysis are performed to justify the selection of antenna dimension.

The organization of the paper is briefed as follows: Section II details the methodology of the proposed design. The influence of various antenna parameters on performance has been explained in the third section. Section IV highlights the comparison between simulation and measured results. Section V concludes the paper.

\section{Antenna Design}

The development stages of the proposed antenna is depict in the Fig. 1. The first stage i.e., Antenna I consists of a rectangular ring $\left(w_{1} \times h_{1}\right)$, strip line $\left(w_{8} \times h_{6}\right)$, incremented strip line $\left(w_{7} \times h_{5}\right)$ and ground palne $\left(w \times h_{7}\right)$. From [21], it is obvious that the tapered feed line gives better performance in terms of $S_{11}$. It is observed from the Fig. 2 that, a dual band operation at 2.5 and $5 \mathrm{GHz}$ is produced by the Antenna I. Then four T-shaped strips are stacked one over another inside the rectangular ring to produce Antenna II. This results in triple band operation as can be seen from the Fig. 2. Further to enhance the impedence bandwidth, a rectangular slot has been etched in the ground. Finally, the proposed antenna is evolved with triple oprating bands with ranges $2.47-2.77 \mathrm{GHz}, 3.3-3.7 \mathrm{GHz}$ and 5.10-6.62 GHz. This range corresponds to WLAN and WiMAX applications. The Fig. 3 

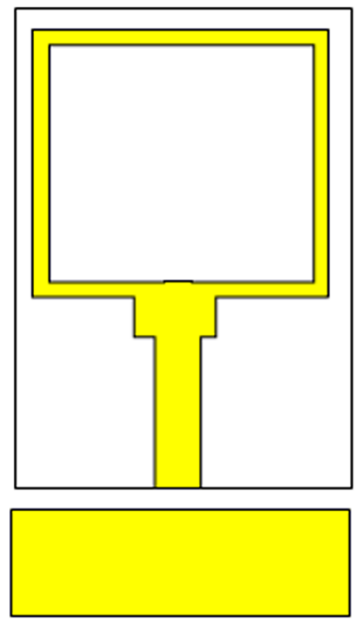

Antenna I
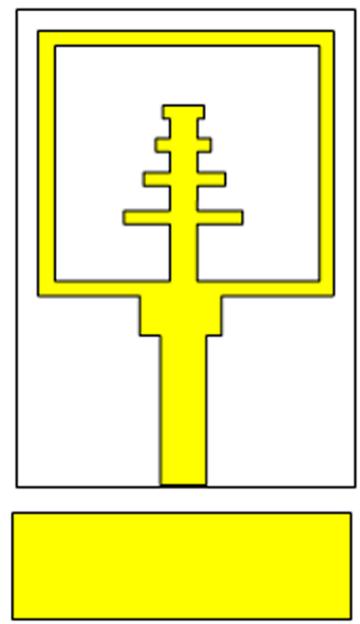

Antenna II
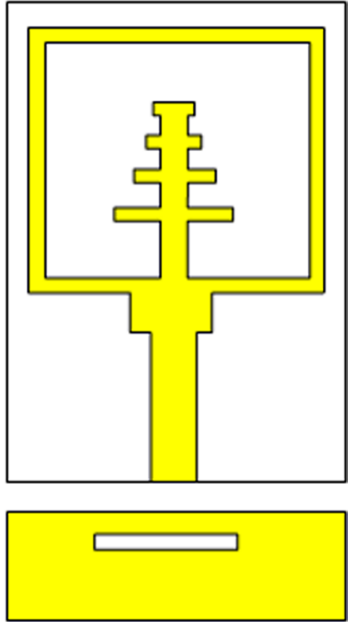

Antenna III

Fig. 1 Development stages of the proposed antenna

Fig. $2 \mathrm{~S}_{11}$ of various antenna in development stages

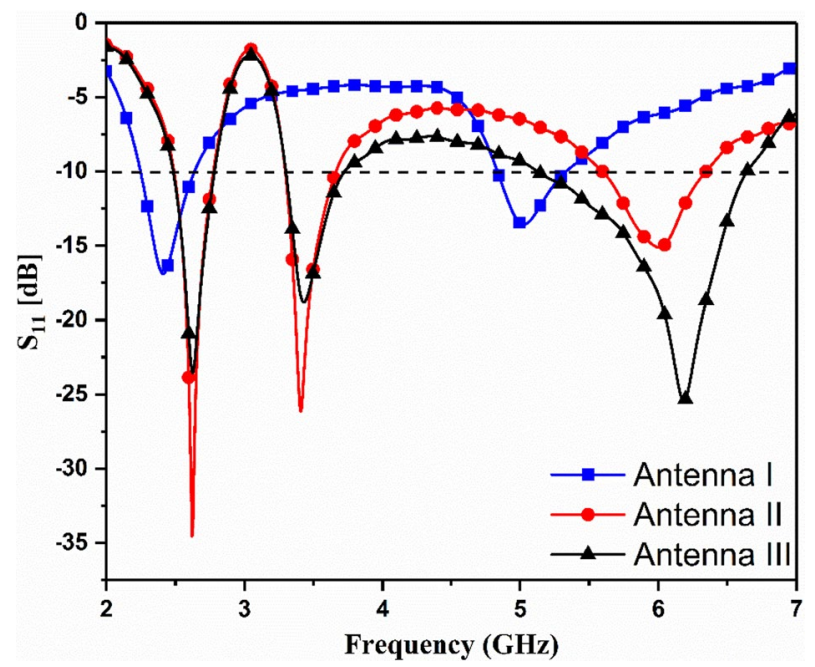

depicts a detailed dimension layout of Antenna III. Figure 4 shows the fabricated antenna. The final dimensions of the proposed antenna are presented in Table 1.

\section{Parametric Analysis}

The influence of various geometric parameters on the frequency parameter characteristics are detailed in parametric analysis. Initially, the effect of various stubs is analyzed. The Fig. 5 illustrates the different structures of the proposed design. The corresponding $S_{11}$ performance is given in the Fig. 6. It is clear from the figure, the final shape marked $w 2$ 

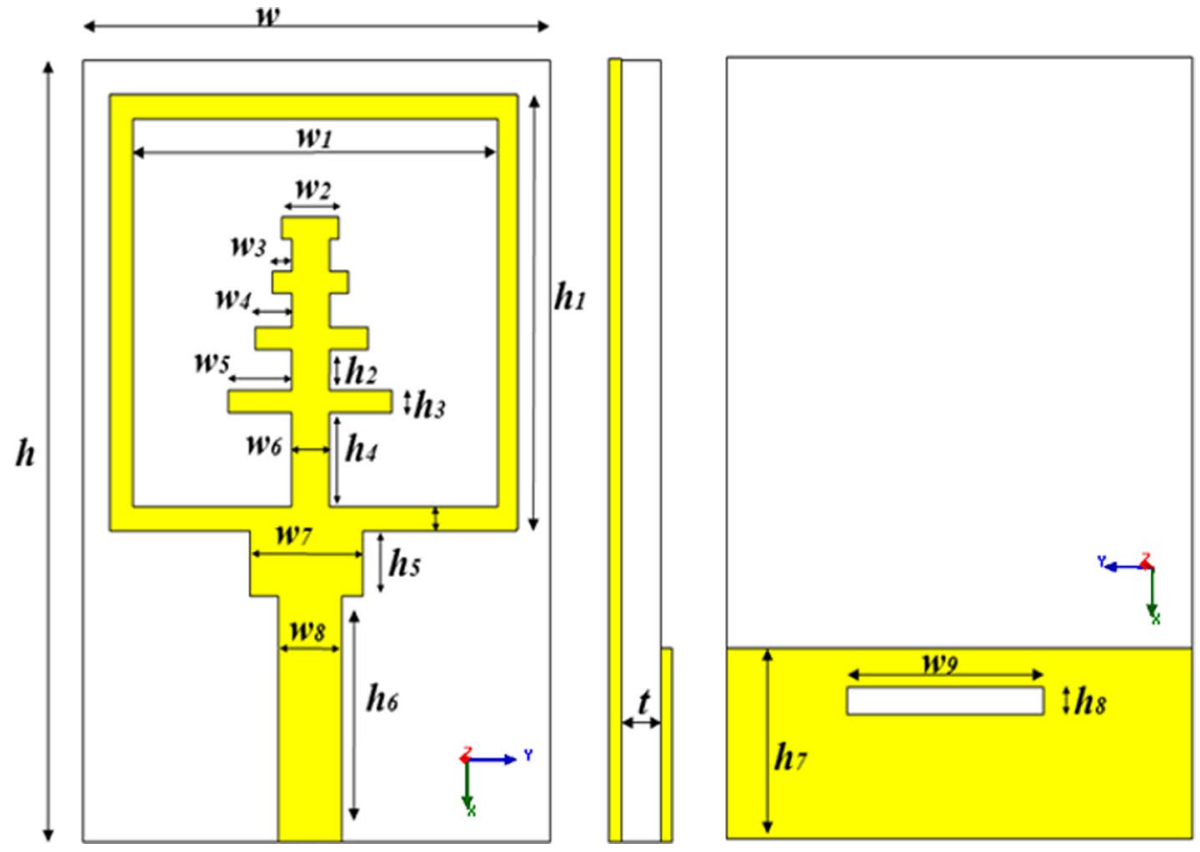

Fig. 3 Geometry of the proposed antenna

Fig. 4 a Front view and b Back view of the fabricated antenna

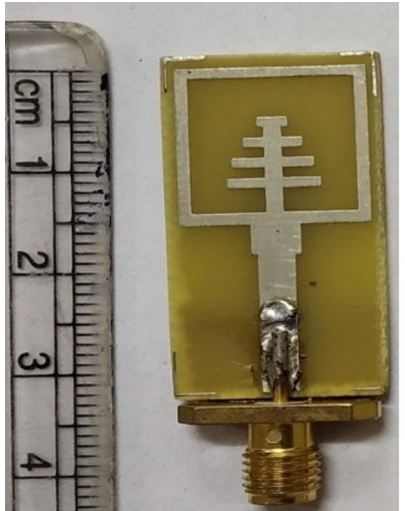

(a)

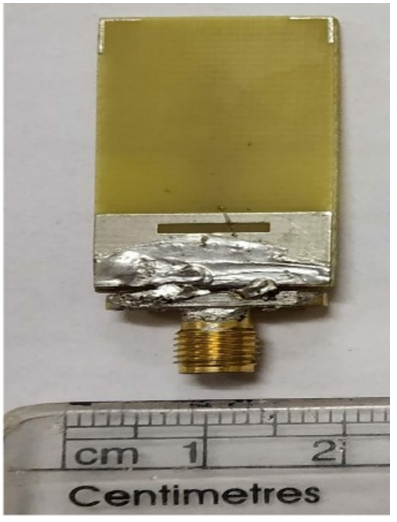

(b)

gives better performance in comparison with other structures. Additionally, it can be easily observed that on adding each stub the performance of the antenna gradually increases. After finalizing the structure, the effect of dimensions of the stubs are studied through parametric analysis.

First, we analyze the effect of variation in length of the ground slot on the $S_{11}$ performance as described in Fig. 7. It can be inferred that $w_{9}=7.2 \mathrm{~mm}$ produces only dual band operation, when $w_{9}$ is increased to $8.2 \mathrm{~mm}$, the antenna operates at three bands. Hence, in the antenna design the ground slot width is chosen as $8.2 \mathrm{~mm}$. 
Table 1 Measurements of the proposed antenna

\begin{tabular}{llll}
\hline Parameter & Size (in mm) & Parameter & Size (in mm) \\
\hline$w$ & 17 & $h$ & 33 \\
$w 1$ & 13.5 & $h 1$ & 17.5 \\
$w 2$ & 2.5 & $h 2$ & 1 \\
$w 3$ & 1.7 & $h 3$ & 1 \\
$w 4$ & 2.7 & $h 4$ & 2.4 \\
$w 5$ & 3.1 & $h 5$ & 3 \\
$w 6$ & 1.4 & $h 6$ & 13.4 \\
$w 7$ & 4 & $h 7$ & 8.7 \\
$w 8$ & 3 & $h 8$ & 1.2 \\
$w 9$ & 8.2 & $t$ & 1.6 \\
\hline
\end{tabular}
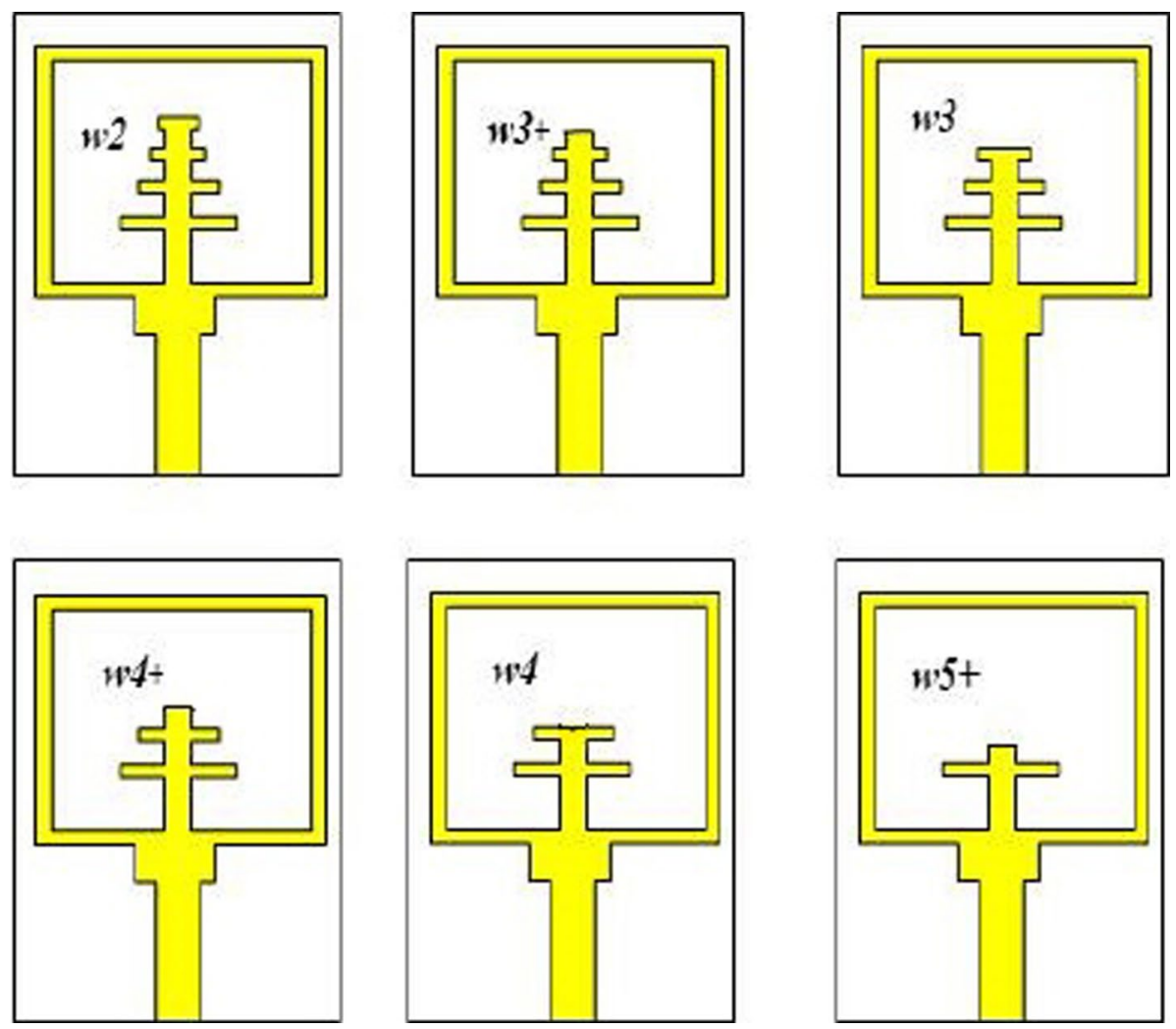

Fig. 5 Different structures of the proposed antenna

Next, to understand the effect of gap between the strips and ring monopole, the length of $h_{4}$ is differed from 1.4 to $3.4 \mathrm{~mm}$. The various $\mathrm{S}_{11}$ performance corresponding to different $h 4$ values are plotted in the Fig. 8 .

It is obvious from Fig. 8 that the length of $h 4$ affects the second operating band at 3.5 GHz. This parameter gives the flexibility of tuning the antenna and set at any frequency 
Fig. 6 S11 for different structures of the proposed antenna
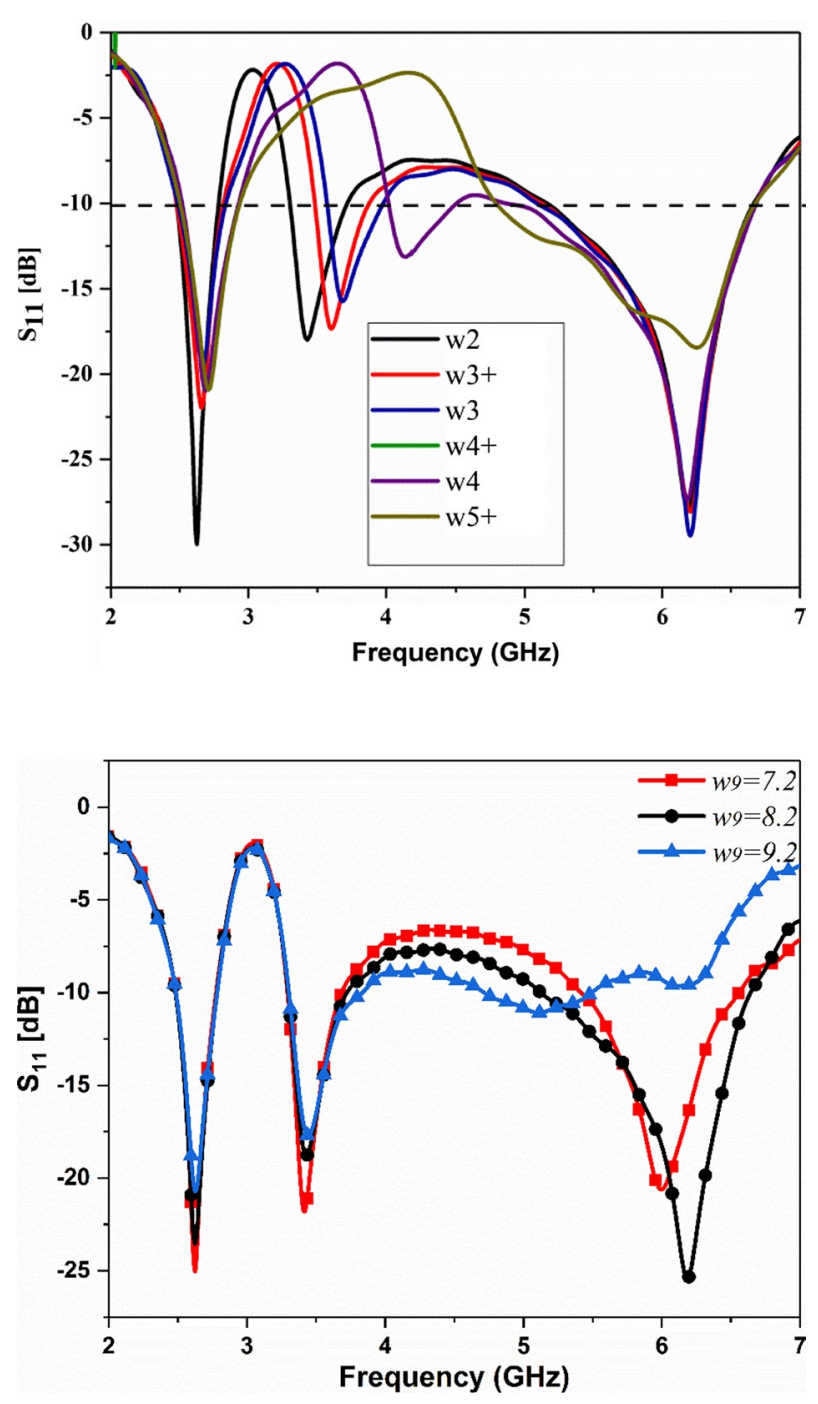

Fig. 7 Variation of S11 with respect to the variation in $w 9$

between 3 and $4 \mathrm{GHz}$. Here, we fixed the length as $2.4 \mathrm{~mm}$ in order to get $3.5 \mathrm{GHz}$ as the operating frequency.

The Fig. 9 shows the variation of S11 for the various values of $w_{5}$. To get the operating band at $3.5 \mathrm{GHz} 3.1 \mathrm{~mm}$ has been chosen for the fabricated antenna. It is observed Fig. 9 that, the other values of $w_{5}$ shifts the operating band towards $3 \mathrm{GHz}$.

\section{Measurement Results}

Agilent N5230A vector network analyzer (VNA) is used to perform the proposed antenna design measurements. The Fig. 10 shows that there is minimal difference between measured and simulated results. Additionally, it can be inferred from the 
Fig. 8 Variation of S11 with respect to the variation in $h 4$

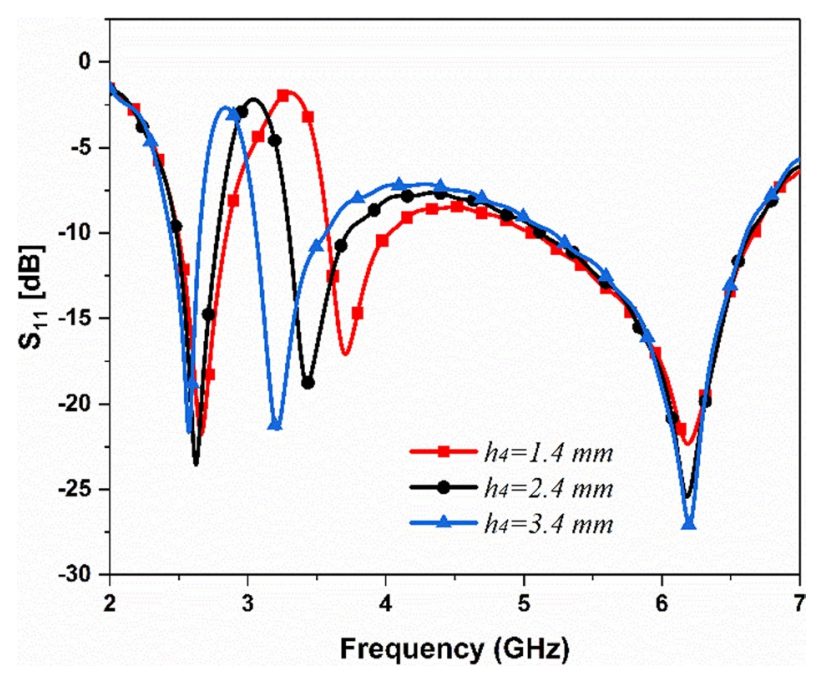

Fig. 9 Variation of $\mathrm{S}_{11}$ with respect to the variation in $w_{5}$

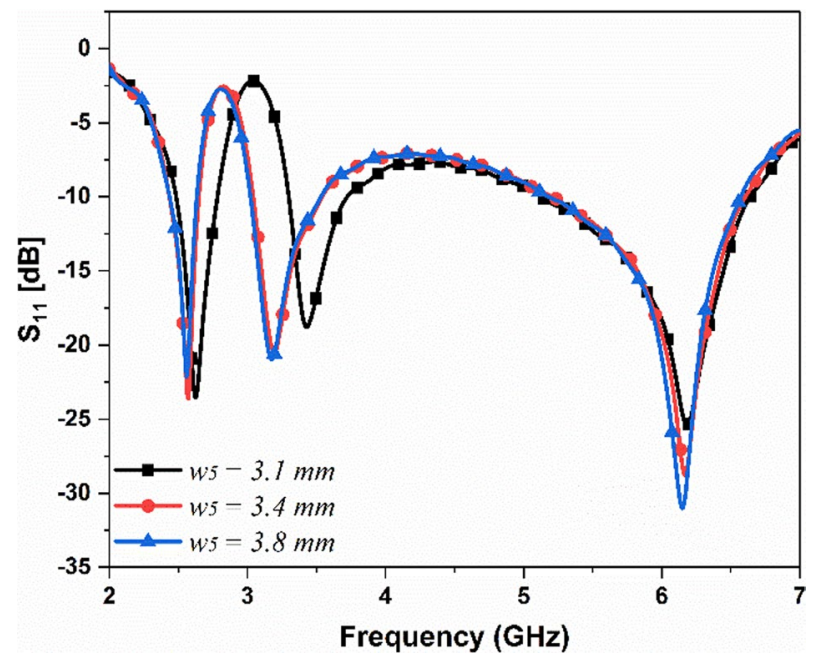

Fig. 10, that three bands of antenna operation are $2.47-2.77 \mathrm{GHz}, 3.3-3.7 \mathrm{GHz}$ and 5.10-6.62 GHz. These operating regions finds application in WLAN and WiMAX standards.

The surface current densities are given in Fig. 11. It is observed from figure that at $2.5 \mathrm{GHz}$, the current concentrates at the peripheral ring. The operating band at $3.5 \mathrm{GHz}$ is due to the current at microstrip line. At $5.5 \mathrm{GHz}$, the current concentrates on ground slot as well as rectangular ring, thus validating the process of antenna design. 
Fig. 10 Comparative analysis between the simulated and measured result

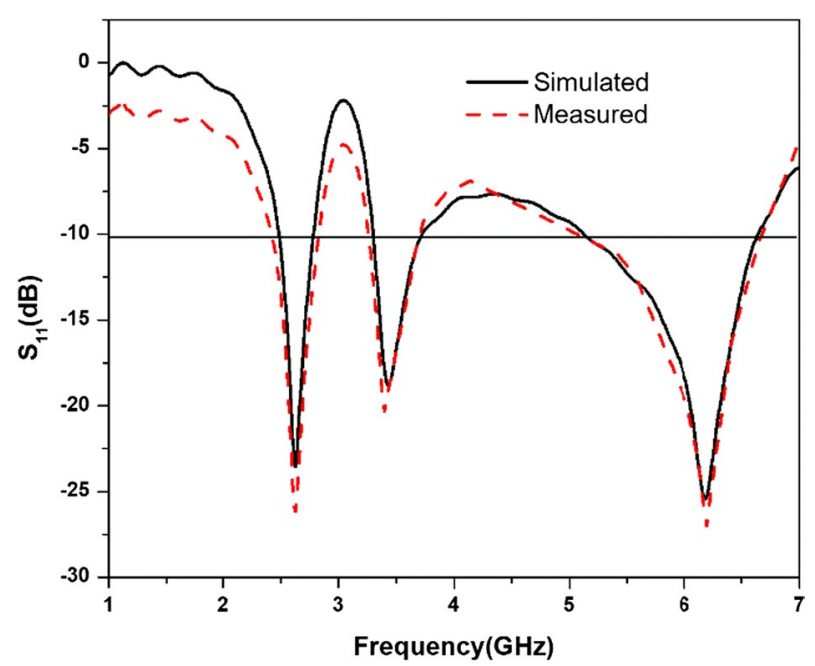

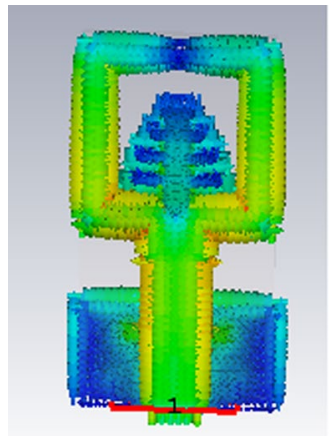

(a)

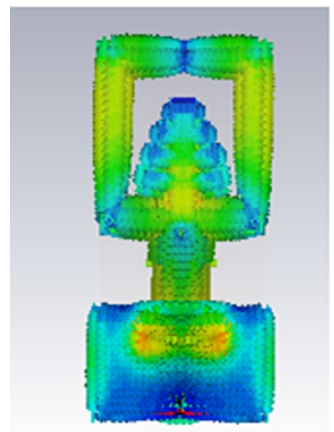

(c)
Fig. 11 Surface current density at a $2.5 \mathrm{GHz}$, b $3.5 \mathrm{GHz}$ and $\mathbf{c}$ $5.5 \mathrm{GHz}$

Figure 12 shows the measured and simulated radiation pattern. The far field radiation pattern exhibits bidirectional pattern at center frequency, i.e., $2.5 \mathrm{GHz}, 3.5 \mathrm{GHz}$ and $5.5 \mathrm{GHz}$ in E-Plane. 

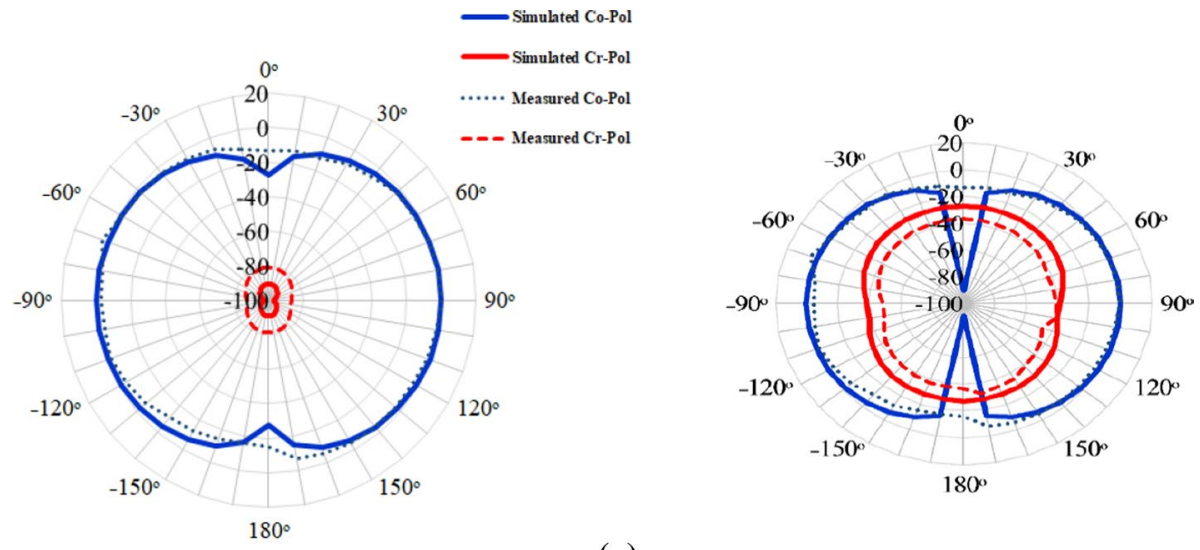

(a)

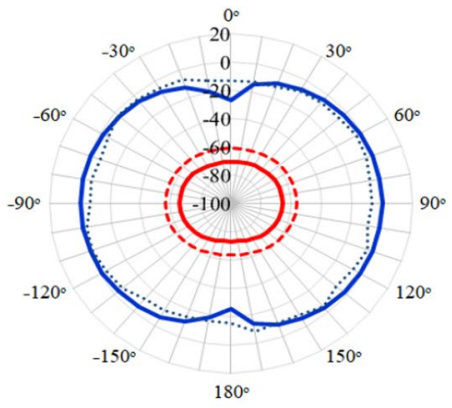

(b)
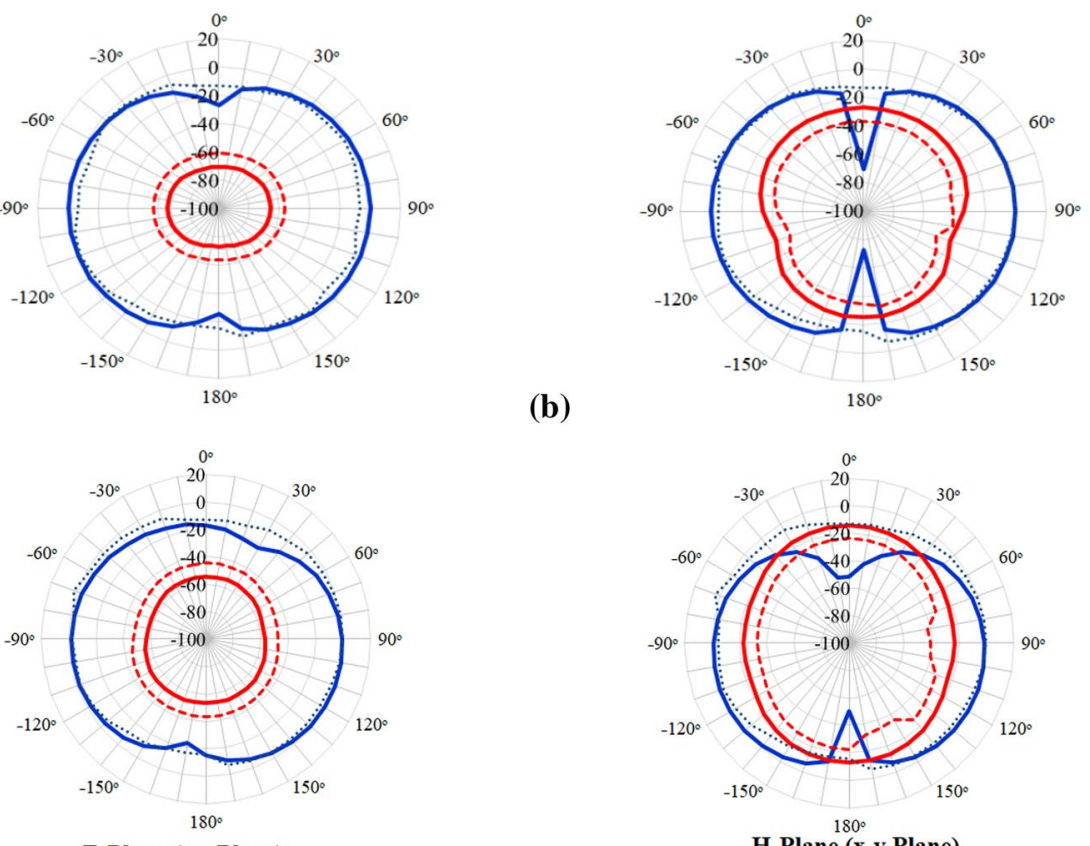

E-Plane ( $x-z$ Plane)

(c)

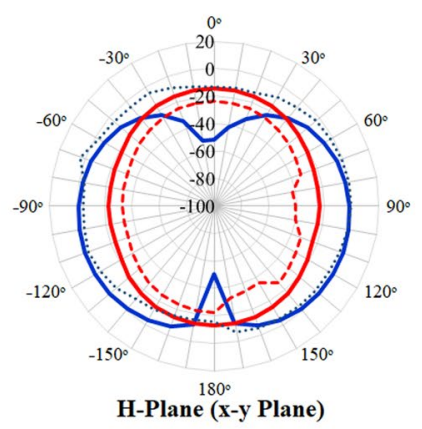

Fig. 12 Simulated and measured radiation patterns of the proposed antenna at a $2.5 \mathrm{GHz}, \mathbf{b} 3.5 \mathrm{GHz}$ and c $5.5 \mathrm{GHz}$

Omni directional pattern is observed in the H-Plane. The antenna gains and radiation efficiency is simulated over the operating ranges. It can be seen from the Fig. 13 that the gain varies from 2 to $3.8 \mathrm{~dB}$ and the efficiency varies from 60 to $80 \%$ over the operating bands. Comparative analysis of the proposed antenna with the existing similar antenna designs is highlighted in Table 2, thus implying the superiority of the proposed design in terms of size, gain and bandwidth over its counterpart. 


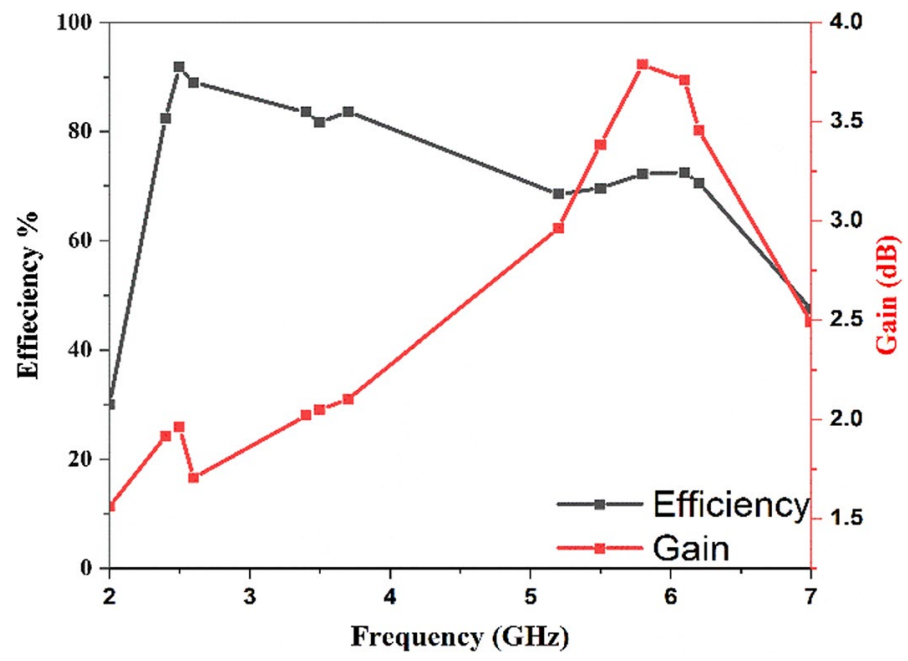

Fig. 13 Simulated gain and efficiency of the proposed antenna

Table 2 Comparison of proposed antenna with the existing designs

\begin{tabular}{llcc}
\hline References & Operating bands $(\mathrm{GHz})$ & Gain $(\mathrm{dB})$ & $\begin{array}{l}\text { Dimension } \\
(L \times W) \text { in } \\
\mathrm{mm}\end{array}$ \\
\hline$[9]$ & $2.34-2.74,3.04-3.82,5.03-6.05$ & $2.36-4.0$ & $33 \times 28$ \\
{$[10]$} & $2.35-2.8,3.4-3.75 .05-6.1$ & $2.36-3.62$ & $38 \times 25$ \\
{$[11]$} & $2.36-2.93,3.34-3.77,4.75-7.28$ & $2-3.9$ & $38 \times 28$ \\
{$[12]$} & $2.4-2.484,3.4-3.69,5.15-5.95$ & $2-4$ & $30 \times 42$ \\
{$[15]$} & $2.40-2.48,5.15-5.30,5.72-5.85$ & $0-4$ & $34 \times 18$ \\
{$[21]$} & $2.41-2.54,3-6.65$ & $1-2.3$ & $33 \times 17$ \\
Proposed work & $2.47-2.77,3.3-3.7,5.10-6.62$ & $2-3.9$ & $33 \times 17$ \\
\hline
\end{tabular}

\section{Conclusion}

A compact triple band antenna has been reported in this research article. The proposed design is compact in nature with dimension of $33 \times 17 \times 1.6 \mathrm{~mm}^{3}$. The printed monopole antenna exhibits triple band operation which supports important wireless communication standards like WLAN and WiMAX. The designed antenna achieves the omni-directional radiation pattern. It also achieves high gain and bandwidth. With these features and compact size, the proposed antenna could easily be adopted for real-time compact wireless communication devices.

Funding Open access funding provided by Manipal Academy of Higher Education, Manipal. 
Open Access This article is licensed under a Creative Commons Attribution 4.0 International License, which permits use, sharing, adaptation, distribution and reproduction in any medium or format, as long as you give appropriate credit to the original author(s) and the source, provide a link to the Creative Commons licence, and indicate if changes were made. The images or other third party material in this article are included in the article's Creative Commons licence, unless indicated otherwise in a credit line to the material. If material is not included in the article's Creative Commons licence and your intended use is not permitted by statutory regulation or exceeds the permitted use, you will need to obtain permission directly from the copyright holder. To view a copy of this licence, visit http://creativecommons.org/licenses/by/4.0/.

\section{References}

1. Ali, T., Fatima, N., \& Biradar, R. C. (2018). A miniaturized multiband reconfigurable fractal slot antenna for GPS/GNSS/Bluetooth/WiMAX/X-band applications. AEU-International Journal of Electronics and Communications, 94, 234-243.

2. Boukarkar, A., Lin, X. Q., Jiang, Y., \& Yu, Y. Q. (2016). Miniaturized single-feed multiband patch antennas. IEEE Transactions on Antennas and Propagation, 65(2), 850-854.

3. Cheng, W., Li, L., Liu, G., Xiao, Y., Wang, Z. Y., \& Yang, J. X. (2016). An interdigital capacitor loaded slot antenna with compact size. Progress In Electromagnetics Research, 64, 15-19.

4. Oloumi, D., Ebadi, S., Kordzadeh, A., Semnani, A., Mousavi, P., \& Gong, X. (2011). Miniaturized reflectarray unit cell using fractal-shaped patch-slot configuration. IEEE Antennas and Wireless Propagation Letters, 11, 10-13.

5. Saadh, A. M., \& Ali, T. (2019). A compact coaxial fed metamaterial antenna for wireless applications. Journal of Instrumentation, 14(06), P06025.

6. Aw, M. S., Ashwath, K., \& Ali, T. (2019). A compact two element MIMO antenna with improved isolation for wireless applications. Journal of Instrumentation, 14(06), P06014.

7. Wu, W. J., Yin, Y. Z., Zhang, Z. Y., Zuo, S. L., \& Xie, J. J. (2012). Loop-loaded monopole antenna with miniaturization and dual-band characteristics. Microwave and Optical Technology Letters, 54(5), 1236-1239.

8. Ali, T., Mohammad Saadh, A. W., Biradar, R. C., Andújar, A., \& Anguera, J. (2018). A miniaturized slotted ground structure UWB antenna for multiband applications. Microwave and Optical Technology Letters, 60(8), 2060-2068.

9. Li, X., Wang, Y. F., Shi, X. W., Hu, W., \& Chen, L. (2012). Compact triple-band antenna with rectangular ring for WLAN and WiMAX applications. Microwave and Optical Technology Letters, 54(2), 286-289.

10. Liu, W. X., Yin, Y. Z., \& Xu, W. L. (2012). Compact self-similar triple-band antenna for WLAN/ WiMAX applications. Microwave and Optical Technology Letters, 54(4), 1084-1087.

11. Li, X., Hu, W., Wang, Y. F., Shi, X. W., \& Gu, X. T. (2012). Printed triple-band rectangular ring monopole antenna with symmetrical L-strips for WLAN/WiMAX applications. Microwave and Optical Technology Letters, 54(4), 1049-1052.

12. Lu, J. H., Zeng, B. R., \& Li, Y. H. (2014). Planar multi-band monopole antenna for WLAN/ WiMAX applications. In: 2014 International Symposium on Antennas and Propagation Conference Proceedings (pp. 475-476). IEEE.

13. Zhang, X. Q., Jiao, Y. C., \& Wang, W. H. (2012). Miniature triple-band CPW-fed monopole antenna for WLAN/WiMAX applications. Progress In Electromagnetics Research, 31, 97-105. 
14. Chouti, L., Messaoudene, I., Denidni, T. A., \& Benghalia, A. (2017). Triple-band CPW-fed monopole antenna for WLAN/WiMAX applications. Progress In Electromagnetics Research, 69, 1-7.

15. Li, L., Zhang, X., Yin, X., \& Zhou, L. (2016). A compact triple-band printed monopole antenna for WLAN/WiMAX applications. IEEE antennas and wireless propagation letters, 15, 1853-1855.

16. Roy, B., Bhattacharya, A., Chowdhury, S. K., \& Bhattacharjee, A. K. (2016). Wideband Snowflake slot antenna using Koch iteration technique for wireless and C-band applications. AEU-International Journal of Electronics and Communications, 70(10), 1467-1472.

17. Peng, L., Sang, S., Wang, Z., Jin, H., Wu, A., Xu, K., \& Wang, G. (2018). Wideband radiation from an offset-fed split ring resonator with multi-order resonances. IEEE Antennas and Wireless Propagation Letters, 17(12), 2198-2202.

18. Ali, T., \& Biradar, R. C. (2017). A compact multiband antenna using $\lambda / 4$ rectangular stub loaded with metamaterial for IEEE 802.11 N and IEEE 802.16 E. Microwave and Optical Technology Letters, 59(5), 1000-1006.

19. Ali, T., Aw, M. S., \& Biradar, R. C. (2018). A fractal quad-band antenna loaded with L-shaped slot and metamaterial for wireless applications. International Journal of Microwave and Wireless Technologies, 10(7), 826-834.

20. Bhattacharya, A., Roy, B., Chowdhury, S. K., \& Bhattacharjee, A. K. (2017). Compact slotted UWB monopole antenna with tuneable band-notch characteristics. Microwave and Optical Technology Letters, 59(9), 2358-2365.

21. Karthikeyan, M., Sitharthan, R., Ali, T., \& Roy, B. (2020). Compact multiband CPW fed monopole antenna with square ring and T-shaped strips. Microwave and Optical Technology Letters, 62(2), 926-932.

Publisher's Note Springer Nature remains neutral with regard to jurisdictional claims in published maps and institutional affiliations.

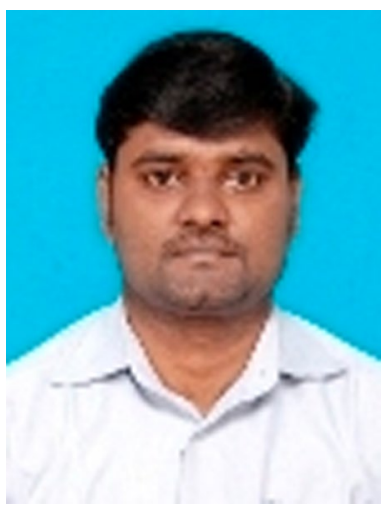

Dr. Madurakavi Karthikeyan is working as an Assistant Professor Senior Grade in School of Electronics, VIT, Vellore. He received his $\mathrm{BE}$ degree in electronics and communication engineering from S.K.P Engineering College, Tiruvannamalai, India, in 2008 and his ME degree in communication systems from Mailam Engineering College, Mailam affiliated to Anna University, Tamilnadu, India, in 2011. He received his PhD in Department of Electronics and Communication Engineering from Pondicherry University, Puducherry, India. His current research area includes MIMO receiver design, wireless energy harvesting in IOT and cyber physical systems, antenna design etc. 

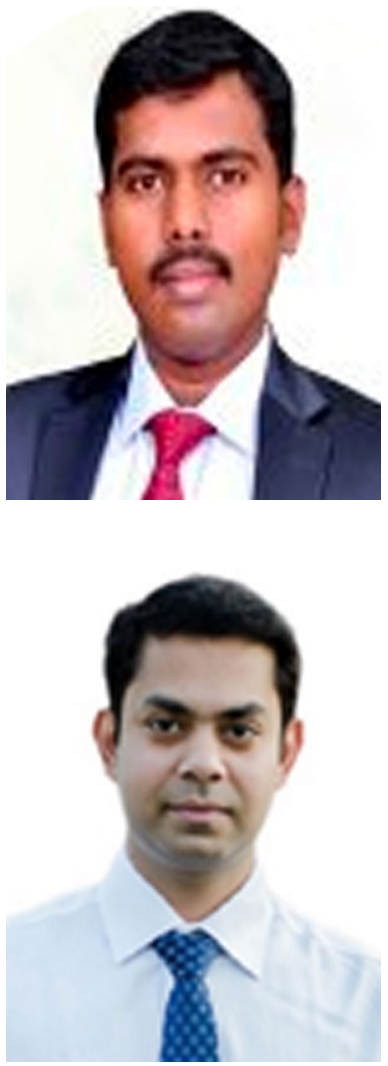

engineering, IEEE Access etc.

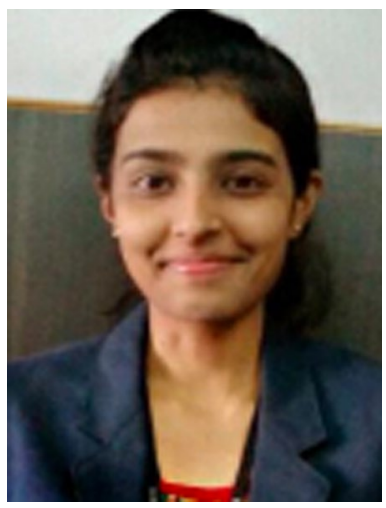

R. Sitharthan is working as an Assistant Professor Senior Grade in School of Electrical Engineering, VIT, Vellore. His current research area includes Distributed generation systems, Artificial Intelligent, controller Power systems, microwave antenna design.

Tanweer Ali is working an Assistant Professor in the Dept. of Electronics \& Communication Engineering at Manipal Institute of Technology, Manipal Academy of Higher Education, Manipal. He is an active researcher in the field of microstrip antennas, wireless communication and microwave Imaging. He has published more than 120 papers in reputed peer reviewed international journal and conferences. $\mathrm{He}$ is a senior member IEEE (SMIEEE), and Associate Member of IETE India. He is on the board of reviewers of journals like the IEEE Transactions on Antennas and Propagation, IEEE Antennas and Wireless Propagation Letters, IET Microwaves, Antennas \& Propagatin, IET Electronics letter, Wireless Personal Communication (WPC), Springer, AEU-International Journal of Electronics and Communications, Microwave and optical Technology letters (MOTL), Wiley, International Journal of Antennas and Propagation, Hindawi., Advanced Electromagnetics, Progress in Electromagnetic Research (PIER), KSII Transaction of Engineering Science, Korea, International Journal of Microwave and Wireless Technologies, Frequenz, Radio

Sameena Pathan has completed PhD at MIT, Manipal. Her research interest includes microwave imaging, dermoscopic image analysis and pattern recognition. She has many publications in reputed national/ international journals and conferences. She is a reviewer of journals published by Springer. 

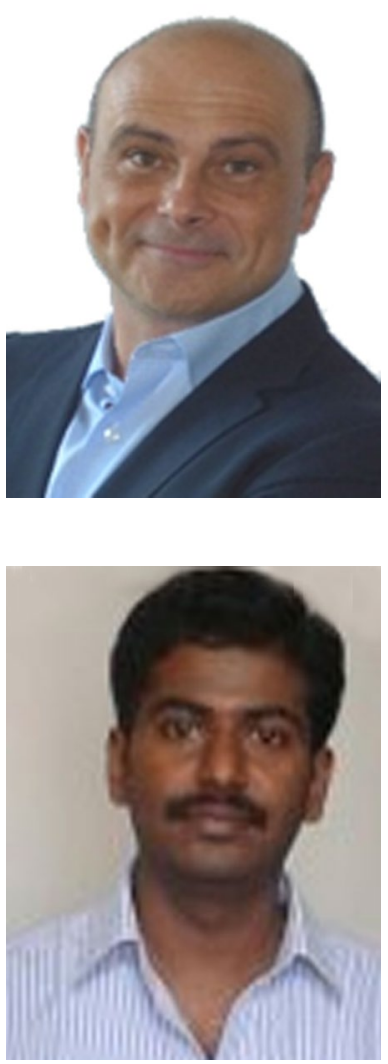

Jaume Anguera $\mathrm{He}$ is reviewer for several IEEE journals as well in others. He is associate editor at Electronics Letters, editor of International Journal on Antennas and Propagation (IJAP) and International Journal on Electronics and Communications. His biography is listed in Who'sWho in the World, Who'sWho in Science and Engineering, Who's Who in Emerging Leaders and in IBC (International Biographical Center, Cambridge-England).His detailed information can be found at: http://users.salleurl.edu/ jaume.anguera.

D. Shanmuga Sundar is an Investigator-Post doctorate, University of Chile, Chile, Santiago. His current research area includes Flexible Electronics, Optical Communication, Photonics, microwave antenna design. 